\title{
DENISE PAHL SCHAAN, A PARCEIRA ACADÊMICA
}

\author{
Jane Felipe Beltrão (iD $\triangle$
}

PPGA-UFPA

Rhuan Carlos dos Santos Lopes (iD $\triangle$

PPGA-UFC/UNILAB

Tallyta Suenny Araújo da Silva (iD $\triangle$

Doutora em Antropologia (UFPA) 
O artigo se constitui em um esforço narrativo sobre a importância do legado de Denise Pahl Schaan, arqueóloga e antropóloga, parceira acadêmica que permaneceu associada à Universidade Federal do Pará (UFPA) de 2004, quando ingressa na instituição, a 2018, quando veio a falecer. Dá-se ênfase à contribuição acadêmica da autora e ao seu legado de qualidade impar relativo à constituição do campo da Arqueologia na UFPA. Foram 14 anos de intenso trabalho, que resultou em inúmeras ações, dentre elas contabilizam-se uma revista, um programa de pós-graduação e a formação de muitosas profissionais.

Palavras-chave: Amazônias; Arqueologia; Antropologia; Denise Pahı Schaan.

\section{DENISE PAHL SCHAAN, THE ACADEMIC PARTNER}

\section{ABSTRACT}

The article is a narrative effort about the importance of the legacy of Denise Pahl Schaan, an archaeologist and anthropologist, an academic partner who remained associated with the Federal University of Pará between 2004, when she joined the institution, and 2018, when she died. Emphasis is placed on the author's academic contribution and her legacy of unique quality regarding the constitution of the field of Archeology at the University. There were 14 years of intense work that resulted in countless actions. Among them are a magazine, a graduate program and the training of many professionals.

\section{DENISE PAHL SCHAAN \\ LA SOCIA ACADÉMICA}

El artículo constituye un esfuerzo narrativo sobre la importancia del legado de Denise Pahl Schaan, arqueóloga y antropóloga, socia académica que permaneció asociada a la Universidad Federal de Pará entre 2004 cuando ingresó a la institución y 2018 cuando falleció. Se enfatiza la contribución académica de la autora y su legado de extraña calidad en cuanto a la constitución del campo de la Arqueología en la Universidad. Fueron 14 años de intenso trabajo que resultaron en innumerables acciones. Entre ellos se encuentran una revista, un programa de posgrado y la formación de muchos profesionales. 


\section{DA PROSA INICIAL}

Conhecemos Denise Pahl Schaan em momentos diferentes de nossas trajetórias, mas por certo a convivência acadêmica com ela marcou indelevelmente nossas carreiras. Eu, como docente e parceira em muitos projetos dentre os quais destaco (i) a Amazônica - Revista de Antropologia, cujo primeiro número veio a lume em março de 2009; e (ii) o Programa de Pós-Graduação em Antropologia (PPGA), aprovado pela Capes, em agosto de 2009, que iniciou em agosto de 2010 e, ainda hoje, é o único programa no Brasil que mantém os quatro campos da Antropologia em seu horizonte.

Com o ingresso de Denise na Universidade Federal do Pará (UFPA) em 2004, e posteriormente com a abertura do PPGA/UFPA, chegaram os muitos discentes que ela auxiliou a "forjar" academicamente. Eles foram muitos/as, aqui escrevo com Rhuan Carlos dos Santos Lopes e Tallyta Suenny Araújo da Silva, pois eles chegam à Antropologia quase ao mesmo tempo, o primeiro como ingresso no mestrado e a segunda como bolsista de iniciação científica.

Escrevo com Rhuan e Tallyta para conseguir forças e não esquecer de Denise como a pessoa que implantou a Arqueologia na UFPA, sem descurar da Antropologia Social que considerava a possibilidade de enraizamento e sustentação dos demais campos de atuação de antropólogos/as.

Sua formação era multifacetada e isso foi a pedra de toque de muitos de seus projetos.

\section{DENISE PAHL SCHAAN SOB SUA PRÓPRIA ÓTICA}

No resumo do Curriculum Vitae de Denise, inscrito na Plataforma Lattes, ela se apresenta como "[1]icenciada em História pela Universidade Federal do Rio Grande do Sul (1987). E prossegue: “[m]estre em História/Arqueologia pela Pontifícia Universidade Católica do Rio Grande do Sul (1996) e Ph.D. em Antropologia Social (Arqueologia) pela Universidade de Pittsburgh (2004)”. Tendo realizado "estágio pós-doutoral junto ao PPGASMuseu Nacional do Rio de Janeiro, sob a supervisão de Antonio Carlos de Souza Lima.”.

Ao nos deixar, ela informava no CV Lattes ser professora associada I da UFPA, junto ao Instituto de Filosofia e Ciências Humanas (IFCH), atuando no PPGA/UFPA, que contempla as áreas de concentração em Arqueologia, Antropologia Sociocultural e Bioantropologia. Àquela altura, ela lecionava na Faculdade de Artes Visuais (FAV/ UFPA), na graduação em Cinema e Audiovisual.

Como pesquisadora, dedicava-se “... à pesquisa antropológica na Amazônia, atuando principalmente nas seguintes áreas: sociedades complexas, ecologia histórica, arqueologia da 
paisagem, antropologia sonora e visual, etnografia audiovisual, gênero, patrimônio cultural e arte.”.

Desenvolveu “... projeto de pesquisa com geoglifos no Acre e em etnografia audiovisual.” Trabalhou “... na produção de filmes documentais e roteiros para audiovisual". Foi membro da Associação Brasileira de Antropologia (ABA), membro da Sociedade de Arqueologia Brasileira (SAB), a qual chegou a presidir, e foi ainda membro da Society for the Anthropology of Lowland South America (SALSA).

Dizemos nós, sem medo de errar, que a descrição deixada na Plataforma Lattes por nossa parceira de Academia é modesta e, sem exageros, tentaremos informar aos/as leitores/as sobre a sua contribuição ao mundo da Antropologia.

\section{PESQUISA E DIVERSIDADE}

As pesquisas orientadas por Denise Schaan se desdobram por múltiplos caminhos abertos, algumas vezes, de forma pioneira nos espaços amazônicos compreendendo estudos cerâmicos e líticos; de paisagem; e de etno-história. Na Arqueologia, ela percorreu da chamada Arqueologia Pública, passando pela Arqueologia Contemporânea, sem descuidar da Arqueologia Histórica, da Regional, e a de Assentamentos. Trabalhou a Teoria Arqueológica como fundamento de seus projetos e pela possibilidade de sedimentar as análises que fez, dentre outros assuntos que mereceram sua atenção.

Suas primeiras orientações em instituições de pesquisa na Amazônia ocorreram no Museu Paraense Emílio Goeldi (MPEG). No ano de 1998, Marinalva Alves e Julice Pimentel pesquisaram, respectivamente, sobre representações antropomórficas e zoomórficas na cerâmica Marajoara. Outros estudos envolveram as tangas cerâmicas marajoaras, como a realizada por Mariana Ximenes Ponte; as representações gráficas da cerâmica Marajoara, estudadas por Tayane Gama; além de pesquisas documentais e bibliográficas, como a produzida por Mário Martins Júnior sobre o Museu do Marajó; e a de Alam Lima sobre os sítios arqueológicos do Arquipélago do Marajó.

Ao chegar à UFPA, Denise Schaan, orientou pesquisas de graduação, iniciação científica, especialização, mestrado, doutorado, afora a supervisão de pós-doc. Muitos foram os temas dessas pesquisas, pois nossa parceira sempre enfrentou desafios, assim sendo, a Teoria Arqueológica, os grafismos rupestres, a Arqueologia Pública, o Turismo Arqueológico, a Arqueologia de Assentamentos, passando pela Arqueologia Contemporânea, a Arqueologia da Paisagem, a cultura material, o patrimônio, a Arqueologia Funerária, a tecnologia cerâmica e 
lítica, além de trabalhos na área de Antropologia Social.

Denise tinha vasta experiência na Arqueologia de algumas regiões, como no Arquipélago do Marajó, no baixo Amazonas, no Tapajós e no Acre. E algumas de suas orientações e coorientações estiveram relacionadas às pesquisas nesses espaços. Ela agregava pessoas e transformava seus projetos em laboratórios de colaboração e aprendizado.

Para a área do Marajó, compulsamos as pesquisas desenvolvidas por Tayane Gama, Margareth Dias, Paulo Israel, Eliana Rodrigues, Giovana Pampolha e Daiana Alves. Tayane Gama pesquisou a iconografia e os grafismos da cerâmica marajorara; Margareth Dias analisou as cerâmicas de um sítio marajoara no rio Goiapi; enquanto Paulo Israel explorou a relação entre Turismo e Arqueologia na região Leste do Marajó; Giovana Pampolha analisou a cerâmica de um sítio sambaqui localizado no atual município de Melgaço (PA); enquanto Daiana Alves pesquisou sobre os bancos marajoaras e sobre a ocupação humana no curso superior do rio Goiapi; enquanto Eliana Rodrigues realizou pesquisa antropológica que versava sobre o uso da terra e dos recursos no Arquipélago do Marajó pensando as questões de identidade e conflitos, temas especialmente caros nas Amazônias.
No Acre, muitos/as foram os/as parceiros/as, e Antônia Damasceno Barbosa, sem dúvida, foi a maior das colaboradoras, sendo assistente de pesquisa de Denise. Sem seu inestimável auxílio, muito da logística e dos diversos campos feitos no Acre teriam sido inviáveis. Elas - Denise e Antonia - se entendiam muito bem.

Outros/as pesquisadores/as estiveram associados/as aos projetos liderados por Denise no Acre, é o caso de Franciele Silva, Rubens Souza, Wagner Silva, Allana Rodrigues, Flora Braga, Maria Ronízia Gonçalves, Ivandra Galberto e Barbara Souza. As pesquisas envolveram análises espaciais e da paisagem entre os sítios geoglifos, como as de Antônia Damasceno, Rubens Souza, Ivandra Galberto e Wagner Silva; da cultura material, como de Barbara Souza e Allana Rodrigues; e dos usos recentes, percepções e relações das pessoas com os locais onde se localizam os sítios geoglifos, a exemplo de Flora Braga, Maria Ronízia Gonçalves e Franciele Silva.

No caso do Acre e dos geoglifos chegamos a realizar programa de educação patrimonial envolvendo as escolas de ensino fundamental e médio, o qual contou com a colaboração de colegas da UFPA, no caso, Agenor Sarraf, Flávio Barros e Jane Beltrão. Contamos, também, com o concurso de Clarisse Jacques, àquela altura doutoranda e orientanda da nossa parceira. Trabalhamos com 
estudantes de diversas faixas etárias que, na condição de moradores de áreas próximas aos geoglifos, poderiam atuar como guardiões/ãs do patrimônio. Reunimos muito material, faríamos um filme e um paradidático, além de escrever artigos científicos. O trabalho foi interrompido quando ela deixou a estrada da vida, em 3 de março de 2018. E assim se passaram três anos.

Na região do Tapajós e redondezas têmse os estudos sobre o sítio Porto de Santarém apresentados por Anna Barbara Silva, Daiana Travassos, Laércio Vaz e Tallyta Suenny. Outros sítios da região foram pesquisados por Aiezer Duarte, Arenildo Silva, Brenda Bandeira, Cristiane Martins, Diego Barros, Joanna Troufflard, Ricardo Rodrigues e Jheuren Costa de Souza.

Sobre o sítio Porto de Santarém, Anna Barbara analisou o material cerâmico de três feições arqueológicas do tipo bolsão encontradas em uma das áreas do sítio. Laércio Vaz pesquisou a cerâmica doméstica e cerimonial. Daiana Travassos analisou o material cerâmico presente em uma das áreas do sítio, que já tinha sido anteriormente reportada por Anna Roosevelt por conter datações antigas para o período formativo do baixo Amazonas. Por fim, Tallyta Suenny analisou o material lítico encontrado nessa área.

Nas redondezas, Aiezer Filho percorreu rotas por rios e igarapés menores entre o Nhamundá e o Trombetas, observando a dispersão do material cerâmico e a circulação dos indivíduos no passado pré-colonial. Cristiane Martins, em suas pesquisas, analisou dois sítios localizados no atual município de Itaituba, observando o material cerâmico e refletindo sobre a ocupação humana na periferia do domínio tapajônico. Joana Troufflard analisou as modificações produzidas por povos indígenas nas paisagens da região do rio Tapajós, como poços, montículos e caminhos. Diego Barros pesquisou as práticas funerárias para o sítio Nossa Senhora do Perpétuo Socorro, no atual município de Itaituba. Arenildo realizou um trabalho de Arqueologia Pública, no qual analisou as relações das pessoas com as pinturas rupestres de Monte Alegre, a partir das narrativas que possuem sobre esse patrimônio. Ricardo Rodrigues, Jheuren Costa de Souza e Brenda Bandeira analisaram o material cerâmico encontrado no sítio Cedro, localizado no atual município de Belterra.

Outras regiões do Pará também foram investigadas a partir de trabalhos orientados por Denise Schaan. Além de pesquisas orientadas tendo como objeto de estudo sítios localizados em outros estados da região amazônica.

Para a Serra dos Carajás, Tallyta Suenny e Ângelo Pessoa abordaram a ocupação humana e as paisagens de sítios arqueológicos, respectivamente, na Serra Leste e na Serra Norte. Uma arqueologia 
da paisagem de Carajás foi abordada por Carlos Augusto Barbosa, que analisou as escolhas e os usos que as pessoas fizeram ao utilizar as cavidades naturais na região serrana do Sul do Pará.

Para a região do rio Tocantins, ainda no Sul do Pará, a pesquisa de Ana Betânia Pimentel voltou-se para a Arqueologia de Assentamento, verificando os padrões existentes entre sítios do médio curso do rio Tocantins, no atual município de Marabá, já a pesquisa de Marlon Prado fez uma análise tecnológica da cerâmica tupiguarani do sítio Bom Jesus 2, as duas merecem registro.

$\mathrm{Na}$ área do rio Xingu, há pesquisas sobre a cultura material de sítios da região feitas por Heitor Vitor Alvaro, que analisou a tecnologia lítica do sítio Praia do Pepino. Sobre o material cerâmico presente no mesmo sítio, Eliane Faria dialogou, em sua pesquisa, com as memórias e histórias dos grupos indígenas Xipaya e Kuruaya, além dos relatos etno-históricos existentes para a região e que deram origem à sua tese de doutoramento.

Dentre os outros estudos de cultura material na região, Raquel Ramos abordou a cerâmica do sítio São José, atual município de Anapu, por meio de uma análise da cadeia operatória de produção da indústria cerâmica. Laurenia Rodrigues também conduziu uma análise do material cerâmico do sítio Jacupi, localizado no baixo Xingu, no atual município de Gurupá. Enquanto Glenda
Consuelo analisou as narrativas sobre o patrimônio arqueológico e a diversidade cultural presentes no atual município de Altamira. Outro legado importante de Denise Schaan no médio Xingu foi o laboratório de Arqueologia agregado ao curso de Etnodesenvolvimento que, mais tarde, deu origem à Casa da Cultura de Altamira, hoje dirigida por Eliane Faria.

Para a capital paraense, no bairro do Guamá, há as pesquisas de Alexandra Borba e Brenda Bandeira sobre a cultura material do sítio Guamá, localizado em parte do campus 3 da Cidade Universitária Prof. José da Silveira Netto. Ainda em Belém, a pesquisa de Ney Gomes sobre o patrimônio e a paisagem urbana nas redondezas do Ver-o-Peso comporá sua tese de doutoramento.

Trabalhando a relação das pessoas com o patrimônio arqueológico e as repercussões para o turismo no caso dessas relações, a hoje docente do PPGA/UFPA, Renata Godoy, teve como objeto de estudo de seu pós-doutorado, diferentes pontos turísticos na cidade de Belém abrangendo do patrimônio edificado a objetos da cultura material, históricos e pré-coloniais, e contou com Denise na supervisão de suas atividades acadêmicas. Essas relações contemporâneas com o passado arqueológico envolvem agentes sociais institucionalizados e "leigos" que estabelecem diferentes tipos de laços e difundem as informações 
sobre o passado de modos variados. Ainda no debate de Arqueologia Contemporânea e Patrimônio, há a pesquisa de Waléria Barros, que trabalhou metodologias de ensino-aprendizagem da educação patrimonial em escolas do Pará, por meio do levantamento de pesquisas e projetos já desenvolvidos sobre essa temática, dentre eles o projeto Conheça o seu município, desenvolvido pela Secretaria Municipal de Educação e Cultura (SEMEC/PMB) e a UFPA.

Para o Nordeste paraense, no atual município de Igarapé-Açu, Rhuan Lopes analisou os diferentes momentos de uso do espaço na vila de Santo Antônio do Prata, analisando a cultura material, a arquitetura e as narrativas sobre essa paisagem em seus diferentes momentos de ocupação. No Prata, trabalhamos em equipe: Denise, André Gonçalves, Rhuan Lopes e Jane Beltrão. Os estudos do Prata associaram Antropologia Social e Arqueologia guiadas pelas memórias dos Tembé/Tenetehara e dos quilombolas desalojados de seus territórios originais pelo esbulho territorial praticado pelo Estado em associação com as missões religiosas. Inúmeras foram as dissertações e as teses produzidas sobre o Prata e seu entorno pelos discentes do PPGA/UFPA.

Para o estado do Amapá, Denise orientou pesquisas na área de Arqueologia Contemporânea, Arqueologia Pública, Arqueologia da Paisagem e tecnologia lítica. Clarisse Jacques debateu sobre a prática da Arqueologia em comunidades locais, tendo como local de pesquisa a comunidade quilombola de Cinco Chagas do Matapi, visando abarcar não apenas os interesses da Arqueologia com a cultura material do passado mais remoto, mas também considerando as histórias, memórias, experiências e diversidade cultural das pessoas que habitam em áreas de sítios arqueológicos. Fabrício Ferreira pesquisou a produção das louças de cerâmica na comunidade Maruanum, no Amapá, e o cotidiano das louceiras, observando as ontologias que permeiam essas práticas. Kleber Souza analisou a cadeia operatória lítica e os usos dos espaços e da paisagem em dois sítios arqueológicos localizados na área da zona costeira do Amapá.

Em Rondônia, Cliverson Pessoa da Silva pesquisou sobre os contextos da ocupação Jaturana no alto rio Madeira, investigando a variabilidade tecnológica, a espacialidade e as mudanças culturais nessa subtradição cerâmica, a partir do material coletado nos sítios Ilha de Santo Antônio e Novo Engenho Velho.

Além dos trabalhos contextuais, Denise orientou ainda pesquisas que versavam sobre teoria e produção de conhecimento arqueológico, como os trabalhos de Mauro Barreto, que resultaram no livro Abordando o passado: uma introdução à 
Arqueologia, publicado em 2010; e a pesquisa de Iniciação Científica de Luiz Henrique de Carvalho, que realizou uma análise crítica sobre a produção científica arqueológica no Brasil.

$\mathrm{Na}$ área da Antropologia, Denise orientou o trabalho de conclusão de curso de Carlos Eduardo Campos voltado à análise das restrições culturais que permeiam as atividades de caça e os tabus alimentares dos Matsigenka; coorientou com Jane Beltrão a tese de doutorado de Luiza MastopLima, que estudou os processos de construção de identidade entre os povos indígenas Aikewára e dos agricultores do Projeto de Assentamento Belo Horizonte, no Sudeste paraense, abordando questões como etnodesenvolvimento, diversidade e identidade cultural, políticas públicas e privadas. E, ainda, orientou em conjunto com Rosa Acevedo, Eliana Teles Rodrigues, que também abordou o tema identidade, nesse caso, a identidade de quilombolas no Noroeste do Arquipélago do Marajó e suas relações sociais, conhecimentos tradicionais, cosmovisões e embates com o agronegócio.

\section{SÍTIOS-ESCOLA, PROJETOS DE PESQUISA E FORMAÇÃO DE ARQUEÓLOGOS}

Depois de mencionar os espaços estudados e os/as pesquisadores/as que cruzaram o caminho de Denise Schaan, vamos nos debruçar sobre a sua expertise em associar pesquisa ao ensino e à extensão no campo da Antropologia.

Sabe-se que a instituição de sítios-escola permite aos estudantes de Arqueologia o exercício de técnicas de pesquisa in situ, além de viabilizar reflexões entre a teoria e prática da disciplina. As atividades desse tipo coordenadas por Denise Schaan foram direcionadas a diferentes níveis de formação acadêmica, incorporando discentes de cursos de graduação e na formação de pósgraduação, para os/as discentes das diversas especializações em Arqueologia ou Patrimônio Arqueológico na Amazônia, fato que permite o diálogo entre estudantes de diferentes níveis de ensino e carreira em busca da profissionalização. No caso específico do PPGA/UFPA, essa experiência incorporou discentes das áreas de concentração do Programa, permitindo o exercício de diálogo entre os quatro campos propostos pelo curso. Frequentemente, os sítios-escola estavam relacionados a projetos de pesquisa - acadêmicos ou voltados ao licenciamento ambiental e possibilitaram a produção de trabalhos monográficos pelos/as orientandos/as de Denise Schaan e algumas de suas colegas de trabalho, caso de Marcia Bezerra e Jane Beltrão.

A partir da vinculação de Denise Schaan com a UFPA, uma das experiências iniciais de sítios-escola foi realizada no contexto do projeto 
Diagnóstico Arqueológico: Parque de Ciências e Tecnologia do Guamá da Universidade Federal do Pará, em Belém no ano de 2008, na qual foi incluída a realização de trabalho de campo de uma turma de estudantes de graduação em História da UFPA. A pesquisa teve continuidade, em laboratório, com duas bolsistas de iniciação científica do curso de Ciências Sociais, nos anos de 2009 e 2017, com apoio do Conselho Nacional de Desenvolvimento Científico e Tecnológico (CNPq), cujos resultados foram referidos anteriormente ao serem apontados os estudos feitos em Belém, Pará. Foi esse projeto que proporcionou suporte para os espaços do laboratório de Arqueologia que hoje leva o nome de nossa saudosa colega.

Em Santarém, as pesquisas no sítio Porto de Santarém, antes referenciadas, foram desenvolvidas em diferentes etapas ao longo de cinco anos, possibilitando a caracterização de padrões de ocupação da paisagem referentes aos períodos de ocupação do Formativo (3500-2800 AP) e a ocupação Santarém (900-1400 a.D.) (Schaan 2010). Vinculado a esse projeto de licenciamento, estudantes de graduação em Ciências Sociais da UFPA, no ano de 2010, participaram do trabalho de campo. No ano anterior, e vinculado ao mesmo projeto, os/as 11 discentes da Especialização em Arqueologia da UFPA realizaram atividades práticas no mesmo sítio, sob coordenação de campo das arqueólogas Maura Imazio da Silveira e Anna C. Roosevelt (Schaan 2012b). Como Denise não descurava das áreas de concentração do PPGA/ UFPA, uma equipe de pesquisa associada à área de Antropologia Social, liderada por Jane Felipe Beltrão, trabalhou com os povos indígenas dos rios Tapajós e Arapiuns (Beltrão 2015), que nossa parceira identificou com importante por associarse a outros tantos e dizia ela, naquela altura, cheia de esperança: “... gerando preciosos frutos, muitos dos quais ainda estão por vir." (Schaan 2015) na apresentação do livro organizado por Jane Beltrão.

No estado do Acre, a execução do projeto Musealização do Geoglifo Tequinho: arqueologia comunitária no Acre, no município de Senador José Guiomar, possibilitou a realização de trabalho de campo de uma turma de Especialização em Gestão e Estudo do Patrimônio Arqueológico, ofertada pela UFPA e desenvolvida na capital Rio Branco. O projeto possuía subsídios da Sociedade de Arqueologia Brasileira (SAB) e da Petrobras. 
Os discentes puderam tanto observar a relevância para o debate sobre as transformações na paisagem da Amazônia pré-colonial, quanto refletir sobre a Arqueologia Comunitária junto aos coletivos humanos que (res)significam o sítio do Tequinho (Beltrão \& Lopes 2018).

No ano de 2012, no contexto pedagógico do PPGA/UFPA, houve a realização da disciplina Tópicos Especiais em Arqueologia: da paisagem ao estudo intra-sítio - Teoria e Método. As atividades teóricas, sem sala de aula, foram conjugadas com práticas de laboratório, na UFPA, e de campo, no sítio Tucumã, localizado no município de Melgaço, no Arquipélago do Marajó. Discentes de graduação e pós-graduação participaram das atividades e, em laboratório, houve continuidade com a pesquisa de iniciação científica Giovana Pampolha de Carvalho intitulada Estudo do sítio sambaqui Tucumã, Melgaço, PA, de 2014.

As atividades de campo, contudo, não estiveram restritas aos sítios-escola. Nos diversos projetos de pesquisa e consultoria técnica, Denise Schaan incorporava os discentes vinculados ao Núcleo de Pesquisa e Ensino em Arqueologia (NPEA) e ao PPGA/UFPA. Os produtos resultantes desses trabalhos, como livros e artigos, demonstram esse seu perfil docente (Martins, Schaan, Veiga e Silva 2010; Schaan 2012a; Schaan e Alves 2015; e Schaan, Ranzi, e Barbosa 2010).

Além disso, a arqueóloga promovia a pesquisa por meio de submissão de projetos a editais das agências de fomento brasileiras, tais como a Capes e o CNPq. Para citar um exemplo, associado a Rhuan Lopes, refere-se à chamada $\mathrm{MCTI} / \mathrm{CNPq} / \mathrm{MEC} /$ CAPES n 43/2013, que apoiou seu projeto Tempos, espaços e cultura material no Prata-Arqueologia Tembé/Tenetehara, oferecendo subsídios para a sua tese de doutoramento defendida no PPGA/ UFPA a partir de artigos. Em associação a outros projetos coordenados por Jane Beltrão, ambos com financiamento da Capes e do CNPq, viabilizou-se as pesquisas de campo, com participação de ambas as professoras do PPGA (Lopes 2017).

Abaixo, elaboramos um quadro com as orientações levadas a termo por Denise Pahl Schaan no PPGA em oito anos. Os trabalhos defendidos encontram-se no site do programa, que por sua vez, também, foi organizado por ela quando da fundação do PPGA. 


\begin{tabular}{|c|c|c|c|}
\hline \multicolumn{4}{|c|}{ Profissionais orientados/as por Denise Pahl Schaan entre 2010 e 2018 no PPGA/UFPA } \\
\hline $\begin{array}{l}\text { Ano de } \\
\text { defesa }\end{array}$ & Dissertação/Tese & Discente & Linha de Pesquisa \\
\hline 2012 & $\begin{array}{c}\text { Arqueologia do baixo Tapajós: ocupação } \\
\text { humana na periferia do domínio } \\
\text { tapajônico }\end{array}$ & $\begin{array}{c}\text { Cristiane Maria Pires } \\
\text { Martins }\end{array}$ & $\begin{array}{l}\text { Indústrias Cerâmicas/ } \\
\text { Mudanças Culturais }\end{array}$ \\
\hline 2012 & $\begin{array}{c}\text { Ocupação indígena na foz do rio } \\
\text { Tapajós (3260 - } 960 \text { AP): estudo do sítio } \\
\text { Porto de Santarém, baixo Amazonas }\end{array}$ & $\begin{array}{c}\text { Daiana Travassos } \\
\text { Alves }\end{array}$ & $\begin{array}{l}\text { Indústrias Cerâmicas/ } \\
\text { Mudanças Culturais }\end{array}$ \\
\hline 2013 & $\begin{array}{l}\text { Até onde vão as cicatrizes deixadas pelo } \\
\text { tempo? A ocupação humana nos sítios } \\
\text { MMX } 09 \text { e MMX } 11 \text { a partir da análise } \\
\text { das peças líticas }\end{array}$ & $\begin{array}{l}\text { Kleber de Oliveira } \\
\text { Souza }\end{array}$ & $\begin{array}{l}\text { Indústrias Líticas/ } \\
\text { Arqueologia da } \\
\text { Paisagem }\end{array}$ \\
\hline 2013 & $\begin{array}{c}\text { As cavidades, as fontes minerais e as } \\
\text { pessoas nos platôs da serra Norte de } \\
\text { Carajás durante o Holoceno }\end{array}$ & Ângelo Pessoa Lima & $\begin{array}{c}\text { Indústrias Líticas/ } \\
\text { Arqueologia da } \\
\text { Paisagem } \\
\end{array}$ \\
\hline 2014 & $\begin{array}{l}\text { Pelas trilhas dos filhos do sol e da lua: } \\
\text { memórias das pinturas rupestres de } \\
\text { Monte Alegre, Pará, Amazônia, Brasil }\end{array}$ & $\begin{array}{l}\text { Arenildo dos Santos } \\
\text { Silva }\end{array}$ & $\begin{array}{c}\text { Arqueologia } \\
\text { Pública/Patrimônio } \\
\text { Arqueológico }\end{array}$ \\
\hline 2014 & $\begin{array}{c}\text { Análise espacial dos sítios monumentais } \\
\text { do Leste da Amazônia Ocidental }\end{array}$ & $\begin{array}{c}\text { Antônia Damasceno } \\
\text { Barbosa }\end{array}$ & $\begin{array}{l}\text { Arqueologia da } \\
\text { Paisagem/Arqueologia } \\
\text { de Assentamentos }\end{array}$ \\
\hline 2014 & $\begin{array}{c}\text { A gente faz a varja: territorialidade, } \\
\text { estratégias de uso de recursos, } \\
\text { identidade e conflitos na Ilha de Marajó }\end{array}$ & Eliana Teles Rodrigues & $\begin{array}{l}\text { Antropologia Social/ } \\
\text { Territorialidade }\end{array}$ \\
\hline 2015 & $\begin{array}{l}\text { Identidade em movimento: a luta de } \\
\text { índios e agricultores por direitos no } \\
\text { Território Sudeste Paraense }\end{array}$ & $\begin{array}{l}\text { Luiza de Nazaré } \\
\text { Mastop-Lima }\end{array}$ & $\begin{array}{l}\text { Antropologia Social/ } \\
\text { Agricultura familiar }\end{array}$ \\
\hline
\end{tabular}




\begin{tabular}{|c|c|c|c|}
\hline 2015 & $\begin{array}{c}\text { Aqui já morou muita gente: Arqueologia } \\
\text { e prática de pesquisa na comunidade } \\
\text { quilombola de Cinco Chagas do Matapi }\end{array}$ & $\begin{array}{l}\text { Clarisse Callegari } \\
\text { Jacques }\end{array}$ & $\begin{array}{l}\text { Arqueologia } \\
\text { Pública/Patrimônio } \\
\text { Arqueológico }\end{array}$ \\
\hline 2015 & $\begin{array}{c}\text { Os contextos arqueológicos e a } \\
\text { variabilidade artefatual da ocupação } \\
\text { Jatuarana no alto rio Madeira }\end{array}$ & $\begin{array}{l}\text { Cliverson Gilvan } \\
\text { Pessoa da Silva }\end{array}$ & $\begin{array}{l}\text { Indústrias Cerâmicas/ } \\
\text { Mudanças Culturais }\end{array}$ \\
\hline 2015 & $\begin{array}{c}\text { Estudo de práticas funerárias no } \\
\text { contexto amazônico }\end{array}$ & Diego Barros Fonseca & Arqueologia Funerária \\
\hline 2016 & $\begin{array}{l}\text { Viagem etno-histórica e arqueológica } \\
\text { ao médio Xingu: memória e história } \\
\text { indígena na Amazônia }\end{array}$ & $\begin{array}{l}\text { Eliane da Silva Sousa } \\
\text { Farias }\end{array}$ & $\begin{array}{l}\text { Arqueologia Pública/ } \\
\text { Etno-Arqueologia }\end{array}$ \\
\hline 2016 & $\begin{array}{c}\text { Do luxo ao lixo: um estudo arqueológico } \\
\text { do material cerâmico dos bolsões } \\
\text { do sítio Porto de Santarém no baixo } \\
\text { Amazonas }\end{array}$ & $\begin{array}{c}\text { Anna Barbara Cardoso } \\
\text { da Silva }\end{array}$ & $\begin{array}{l}\text { Indústrias Cerâmicas/ } \\
\text { Formação do registro } \\
\text { arqueológico }\end{array}$ \\
\hline 2016 & $\begin{array}{c}\text { Desde que me entendi: tecendo } \\
\text { saberes e fazeres relativos à louca da } \\
\text { comunidade do Maruanum, Amapá/PA }\end{array}$ & Fabrício Costa Ferreira & $\begin{array}{c}\text { Arqueologia Pública/ } \\
\text { Patrimônio arqueológico }\end{array}$ \\
\hline 2017 & $\begin{array}{c}\text { Tempos, espaços e cultura material } \\
\text { na Vila Santo Antônio do Prata: } \\
\text { Arqueologia em uma instituição total } \\
\text { amazônica }\end{array}$ & $\begin{array}{l}\text { Rhuan Carlos dos } \\
\text { Santos Lopes }\end{array}$ & $\begin{array}{l}\text { Arqueologia História/ } \\
\text { Arqueologia da } \\
\text { Repressão e da } \\
\text { Resistência }\end{array}$ \\
\hline \multicolumn{4}{|c|}{$\begin{array}{c}\text { Profissionais cuja orientação foi abruptamente interrompida quando } \\
\text { Denise Pahl Schaan faleceu em } 3 \text { de março da } 2018\end{array}$} \\
\hline 2015 & $\begin{array}{l}\text { Estudo arqueométrico da cerâmica de } \\
\text { sítios tipo geoglifo }\end{array}$ & $\begin{array}{c}\text { Antônia Damasceno } \\
\text { Barbosa }\end{array}$ & $\begin{array}{c}\text { Arqueologia da } \\
\text { Paisagem/Arqueometria }\end{array}$ \\
\hline 2016 & $\begin{array}{c}\text { Escolhas e usos de cavidades naturais } \\
\text { na Amazônia: o caso das regiões de } \\
\text { Maracá (AP), Monte Alegre e Carajás } \\
(P A), \text { Brasil }\end{array}$ & $\begin{array}{l}\text { Carlos Augusto } \\
\text { Palheta Barbosa }\end{array}$ & $\begin{array}{l}\text { Arqueologia da } \\
\text { Paisagem/Arqueologia } \\
\text { de Assentamentos }\end{array}$ \\
\hline 2016 & $\begin{array}{c}\text { Riquezas da terra: paisagens e } \\
\text { ocupações na Serra Leste de Carajás }\end{array}$ & $\begin{array}{l}\text { Tallyta Suenny Araújo } \\
\text { da Silva }\end{array}$ & $\begin{array}{l}\text { Arqueologia da } \\
\text { Paisagem/Cultura } \\
\text { material }\end{array}$ \\
\hline 2017 & $\begin{array}{c}\text { Para além da Arquitetura, a construção } \\
\text { da paisagem através dos olhares e usos } \\
\text { do Ver-o-Peso: uma etnografia visual do } \\
\text { patrimônio }\end{array}$ & Raimundo Ney Gomes & $\begin{array}{l}\text { Arqueologia da } \\
\text { Paisagem/Arqueologia } \\
\text { Pública }\end{array}$ \\
\hline
\end{tabular}




\section{CONCLUSÃO EM ABERTO}

Nosso esforço de relembrar a parceira que foi Denise Pahl Schaan diz respeito tanto aos afetos que nutrimos por ela, como corresponde também ao esforço de registrar seu legado para a UFPA, o qual é ímpar. Quando dizemos da singularidade do legado, nos referimos à implementação da Arqueologia em nossa instituição.

$\mathrm{Na}$ UFPA, desde os/as docentes pioneiros/ as na Antropologia, o desejo de fazer florescer a Arqueologia sempre foi acalentado e nutrido pelos/as antropólogos/as que estão de algum modo relacionados/as ao Laboratório de Antropologia Arthur Napoleão Figueiredo, o qual leva o nome daquele que instituiu o campo da Antropologia entre nós.

No momento da constituição da Antropologia, Napoleão Figueiredo utilizava de um expediente de colaboração com o MPEG, a partir do qual Eduardo Galvão, Mário Simões, Protázio Frikel e ele constituíram muitas das coleções etnológicas e arqueológicas de ambas as instituições.

Denise Pahl Schaan implantou a Arqueologia na UFPA sem descuidar das conexões tão necessárias e deixando formados/as muitos/ as arqueólogos/as que hoje se espalham por instituições localizadas em diversos pontos do país e fora do país. Profissionais capazes que, a partir da sua formação, galgaram novos espaços pela capacidade que adquiriram. Rhuan Lopes foi o último doutorando que Denise coordenou a defesa de tese, Jane Beltrão estava na banca e Tallyta Suenny na plateia.

Quando Denise partiu, Tallyta ficou sem orientadora e passou a ser orientada por Jane Beltrão, juntas realizamos o trabalho com desvelo e in memoriam da parceira de muitas lutas e sonhos em comum.

Daiana Travassos, hoje docente do PPGA, é uma das pessoas que Denise acompanhou da iniciação científica ao doutorado, a Arqueologia feita na UFPA possui as mãos da nossa parceira, razão pela qual não há conclusão possível, pois ela soube deixar os espaços de continuidade em aberto.

Referimo-no, para finalizar, ao trabalho de pósdoc que Denise Pahl Schaan não teve oportunidade de deixar como legado, pois estava analisando os dados coletados sobre Ciência e Estado na institucionalização da Arqueologia Brasileira (19001950), investigação que tinha por foco a análise crítica de documentos primários e fontes secundárias relativas à História da Arqueologia no período entre 1900-1950. No qual ela tentaria aproximar, com ênfase nas articulações entre Arqueologia e Etnologia, nos contextos sociopolíticos da primeira República e do Estado Novo. 
Ela pretendia oferecer especial atenção à prática científica e suas relações com a sociedade e o Estado, buscando compreender como se construiu a imagem sobre o passado do país e os povos indígenas a partir da Arqueologia e da Etnologia. Projeto que ela justificou pela importância da articulação feita a partir da disciplina História do Pensamento Antropológico (HPA), obrigatória para os discentes do PPGA/ UFPA. Denise afirmara em seu projeto de pósdoc, que durante os cinco anos em que lecionou a disciplina observou a carência de literatura que abordasse de maneira mais analítica as articulações entre Arqueologia e os demais campos antropológicos na primeira metade do século XX. Uma vez que a Antropologia se institucionalizou nas instituições universitárias e a Arqueologia a partir de museus, fato que talvez tenha contribuído para se acreditar que a pesquisa arqueológica acadêmica ou científica se inicia realmente somente a partir de meados do século XX (Schaan 2015). Uma vez mais, Denise Schaan se preocupava com o referencial acadêmico necessário à formação de novos profissionais na área da Antropologia para atuar na Amazônia tão reverenciada pela gaúcha que se estabeleceu no Norte e que, ao partir, nos deixou sem a parceria de quase 20 anos. 


\section{REFERÊNCIAS}

Beltrão, J. F. Organizadora. 2015. Povos Indígenas nos rios Tapajós e Arapiuns. Belém: Supercores.

Beltrão, J. F., R. C. D. S. Lopes. 2018. Teorias/teses nativas e arqueológicas sobre os Geoglifos no Acre. Revista Memória em Rede 10(18):4-21.

Lopes, R. C. D. S. Tempos, espaços e cultura material na Vila Santo Antônio do Prata, Pará - Arqueologia em uma instituição total amazônica. 2017. Tese de Doutorado. Programa de Pós-Graduação em Antropologia, Universidade Federal do Pará, Brasil.

Martins, C. M. P., D. P. Schaan, W. Veiga, e E. Silva. 2010. Muito além dos campos - Arqueologia e história na Amazônia Marajoara. Belém: GK Noronha.

Schaan, D. P. 2015. Apresentação, in Povos Indígenas nos rios Tapajós e Arapiuns. Organizado por J.

F. Beltrão, pp. 1-34. Belém: Supercores.

Schaan, D. P. 2010. Salvamento Arqueológico do Sítio PA-ST-42: Porto de Santarém. UFPA/CDP. Relatório Final.

Schaan, D. P. 2012a. Arqueologia, patrimônio e multiculturalismo na beira da estrada: pesquisando ao longo das rodovias Transamazônica e Santarém-Cuiabá, Pará. Belém: GKNoronha.

Schaan, D.P. 2012b. Salvamento arqueológico do sítio PA-ST-42: porto de Santarém - ano 2. UFPA/ CDP. Relatório Final. v. 2.

Schaan, D.P., e D.T. Alves. 2015. Um porto, muitas histórias: Arqueologia em Santarém. Belém: Gráfica Supercores.

Schaan, D. P., A. Ranzi, e A. D. Barbosa. 2010. Geoglifos, paisagens da Amazônia Ocidental. Rio Branco: GKNoronha. 